\title{
PENGUKURAN RESIKO \\ MANAJEMEN PROYEK TEKNOLOGI INFORMASI PADA PT MSI
}

\author{
Henny Hendarti; Firman A.; Desy Deviaty \\ Computerized Accounting Department, School of Information Systems, Binus University \\ Jl. K.H. Syahdan No. 9, Palmerah, Jakarta Barat 11480 \\ henny@binus.edu
}

\begin{abstract}
ABSTRAK
Pengukuran resiko manajemen proyek teknologi informasi ini bertujuan untuk mengetahui bagaimana penerapan manajemen proyek teknologi informasi (TI) berjalan pada PT MSI agar penerapannya dapat sesuai dengan tujuan bisnis yang diharapkan oleh perusahaan dan memperkirakan resiko-resiko apa yang mungkin terjadi. Metode penelitian yang digunakan adalah studi kasus di mana teknik pengumpulan data meliputi studi kepustakaan serta studi lapangan yang meliputi wawancara, kuesioner, dan studi dokumentasi. Pendekatan untuk melakukan pengukuran resiko teknologi informasi pada PT MSI adalah PMBOK (Project Management Body Of Knowledge). Hasil yang dicapai adalah ditemukannya resiko-resiko yang mungkin terjadi pada proyek. Simpulan dari penelitian ini adalah PT MSI sudah menerapkan manajemen proyek teknologi informasi dengan cukup baik melalui proses inisiasi, perencanaan, pelaksanaan dan pengendalian, evaluasi proyek dan penutupan proyek. Hal ini dilihat resiko yang ditemukan tidak banyak dan hanya dibutuhkan sedikit perbaikan dalam mengelola resiko pada proyek tersebut. Namun perusahaan belum melakukan pengukuran terhadap resiko manajemen proyek TI.
\end{abstract}

Kata kunci: pengukuran resiko manajemen, proyek teknologi informasi, Project Management Body Of Knowledge

\begin{abstract}
The risk management measurement of information technology project aims to determine how the application of information technology (IT) project management runs at PT MSI so that their application may in accordance with business objectives expected by the company as well as estimate any risks that may occur. The research uses a case study method in which data collection is gained from literature study and field study by interviews, questionnaires, and study documentation. Approach to measure the risks in information technology at PT MSI is PMBOK (Project Management Body of Knowledge). The research discovers several risks that may occur on the project. Through this research PT MSI is found implementing a quite good information technology project management through the process of initiation, planning, implementation and control, project evaluation and project closure. Only a few risks are found as well as a little improvement to pursuit in the project managing risk. However, the company has not performed any measurements of the IT project management risk.
\end{abstract}

Keywords: risk management measurement, information technology project, Project Management Body of Knowledge 


\section{PENDAHULUAN}

Penerapan teknologi dalam perusahaan memerlukan perencanaan yang strategis khususnya penerapan teknologi pada manajemen proyek, agar penerapan dapat sesuai dengan tujuan bisnis yang diharapkan. Jika tidak sesuai dengan tujuan bisnis yang diinginkan, penerapan teknologi informasi dalam manajemen proyek akan menimbulkan resiko yang dapat menyebabkan proses bisnis tidak optimal, kerugian finansial, menurunnya reputasi perusahaan, bahkan hancurnya perusahaan. Pada kenyataaannya penerapan manajemen proyek teknologi informasi membutuhkan investasi yang cukup besar. Teknologi yang terus berkembang dari waktu ke waktu membuat proses manajemen proyek pun menjadi semakin sulit karena harus memahami teknologi yang baru.

Manajemen resiko teknologi informasi banyak berperan penting hampir dalam seluruh aspek fungsional perusahaan. Manajemen resiko teknologi informasi adalah masalah yang kompleks. Satu yang terpenting dari proses ini adalah analisis resiko yang berguna untuk mengoptimalkan dan meminimalisir kerugian yang berhubungan dengan resiko (WCECS, 2008). Dengan adanya manajemen resiko proyek yang didukung dengan penggunaan hardware diharapkan dapat membantu perusahaan dalam hal meminimalkan tingkat kerugian yang tidak diinginkan oleh perusahaan. Maka dari itu diperlukannya pengelolaan proyek yang baik agar suatu proyek dapat berjalan sukses.

PT MSI adalah perusahaan yang bergerak dalam bidang bergerak di bidang Computer Network dan System Integrator yang menyediakan solusi teknologi informasi dan fitur-fitur maupun layanan yang terbaik bagi komunikasi bisnis yang fleksibel dan efektif bagi para pelanggannya. PT MSI menawarkan proyek-proyek teknologi informasi termasuk menjual fitur-fitur canggih seperti IP telephony, messaging dan contact center, firewall terkelola, dan memonitor jaringan server.

Perusahaan ini terus melakukan peningkatan kualitas manajemen sumber daya manusia dan peningkatan kualitas proyek kepada pelanggan yang didukung dengan adanya pemanfaatan teknologi informasi secara terus-menerus. Dengan tujuan untuk mempertahankan eksistensi dalam dunia bisnis, PT MSI menggunakan teknologi informasi dalam manajemen proyek di dalam perusahaan. Proyek yang dijalankan perusahaan bergantung dari teknologi yang digunakan. Penggunaan produk teknologi informasi pada manajemen proyek akan mendukung aktivitas perusahaan agar dapat berjalan lebih efisien dan efektif. Dalam manajemen proyek teknologi informasi terdapat resiko-resiko yang mungkin terjadi yang berkaitan dengan biaya, waktu dan kualitas proyek, di mana perusahaan harus mampu mengelola resiko manajemen proyek teknologi informasi tersebut. Permasalahan yang dihadapi adalah PT MSI belum pernah melakukan pengukuran resiko terhadap manajemen proyek teknologi informasi. Maka dari itu, untuk menunjang manajemen proyek teknologi informasi yang baik dan memadai, penulis melakukan pengukuran resiko terhadap manajemen proyek pada PT MSI.

Untuk memperjelas penyusunan penelitian ini, diperlukan pembatasan ruang lingkup penelitian antara lain: (1) penelitian dilakukan pada proyek Jardiknas dan proyek RSJPDHK yang terkait dengan PT MSI; (2) penelitian dilakukan untuk mengukur probabilitas dan dampak dari hasil identifikasi resiko pada proyek teknologi informasi yang terkait dengan PT MSI; (3) penelitian dilakukan berdasarkan pendekatan PMBOK (Project Management Body Of Knowledge) untuk mengukur resiko manajemen proyek teknologi informasi yang terkait dengan PT MSI. Adapun tujuan dari penelitian ini yaitu: (1) melakukan pengukuran resiko terhadap manajemen proyek teknologi informasi yang terkait dengan PT MSI; (2) mengidentifikasi resiko-resiko terhadap manajemen proyek teknologi informasi yang terkait dengan PT MSI; (3) memberikan solusi yang terbaik bagi perusahaan untuk mengelola resiko proyek teknologi informasi.

Hasil dari pengukuran resiko tersebut diharapkan dapat mengetahui tingkat resiko dari manajemen proyek teknologi informasi dalam perusahaan dan dapat memberikan masukan dan 
membawa dampak positif bagi perusahaan. Hasil pengukuran resiko dapat digunakan untuk perusahaan sebagai referensi untuk menyempurnakan manajemen proyek teknologi informasi dan sebagai sarana bagi perusahaan untuk menambah pengetahuan dalam manajemen resiko proyek. Dengan adanya penemuan resiko-resiko yang berkaitan dengan proyek pada PT MSI menjadikan perusahaan dapat mengetahui resiko-resiko apa saja yang mungkin dapat muncul dalam suatu proyek. Selain itu penelitian ini dapat memberikan rekomendasi alternatif bagi perusahaan untuk mengantisipasi resiko yang akan muncul pada pengerjaan proyek-proyek di masa yang akan datang.

\section{METODE}

Penelitian ini dengan menggunakan pendekatan kualitatif yang dilakukan terhadap salah satu perusahaan swasta yang ada di Indonesia, yaitu PT MSI. Penulis menggunakan metode studi kasus untuk penelitian ini, di mana datanya tidak hanya diperoleh dari kasus yang diteliti, tetapi juga diperoleh dari semua pihak yang mengetahui dan mengenal kasus tersebut dengan baik. Masalah yang berkaitan dengan studi kasus yang dilakukan pada PT MSI, yaitu mengidentifikasi resiko dan menentukan probabilitas dan dampak resiko yang mungkin terjadi pada manajemen proyek teknologi informasi, di mana penulis melakukan pengukuran resiko manajemen proyek teknologi informasi di perusahaan untuk mengetahui bagaimana manajemen proyek teknologi informasi yang sudah diterapkan oleh perusahaan. Dalam penelitian ini, data yang diperlukan diperoleh dari metode pengumpulan data, sebagai berikut: (1) penelitian kepustakaan - penelitian ini dilakukan dengan cara mengumpulkan data secara tertulis, baik dari buku literatur, artikel-artikel maupun tulisan-tulisan ilmiah yang terkait dengan masalah yang dibahas guna mendukung dan melengkapi penelitian secara tertulis; (2) penelitian lapangan - ada dua metode dalam melakukan penelitian lapangan, yaitu: (a) wawancara (interview) - peneliti melakukan wawancara langsung dengan bagian Project Manager untuk memperoleh gambaran secara rinci mengenai siklus manajemen proyek teknologi informasi di perusahaan, serta untuk memperoleh data perusahaan yang dibutuhkan selama penelitian; (b) studi dokumentasi - mengumpulkan dokumentasi yang terkait yang digunakan oleh perusahaan dalam menjalankan kegiatan operasional perusahaan yang berhubungan dengan masalah yang diteliti guna mendukung data yang telah diperoleh dari hasil wawancara.

Dalam melakukan pengukuran resiko terhadap manajemen proyek TI pada PT MSI, ada banyak metode yang dapat digunakan, salah satunya adalah metode Project Management Body of Knowledge (PMBOK). Metode ini merupakan standar yang ditetapkan oleh American National Standard, ANSI/PMI 99-001-2004 yang diterbitkan oleh Project Management Institute (PMI). PMBOK adalah panduan yang berisikan kumpulan pengetahuan yang diperlukan oleh para profesional dalam manajemen proyek. Tujuan utama dari PMBOK adalah melakukan identifikasi secara bagian per bagian dari pengetahuan atas Badan Pengelola Proyek (Project Management Body of Knowledge) yang secara umum dikenal sebagai praktek terbaik. Maka dari itu, penulis memutuskan untuk menggunakan metode PMBOK untuk mengukur resiko manajemen proyek teknologi informasi pada PT MSI.

\section{HASIL DAN PEMBAHASAN}

\section{Proses Bisnis Perusahaan}

PT MSI mengembangkan suatu proyek yang memiliki jadwal, instalasi dan konfigurasi sistem yang cukup kompleks. Misalnya adalah instalasi sistem PBX pada PT SI, dimana PT MSI pada proyek 
ini melakukan instalasi pada lebih dari 20 cabang PT SI di seluruh Indonesia, dan juga melakukan desain, konfigurasi sistem voice sehingga dapat lebih efektif dan efisien.

Adapun proses manajemen proyek tersebut adalah (Gambar 1 dan 2):

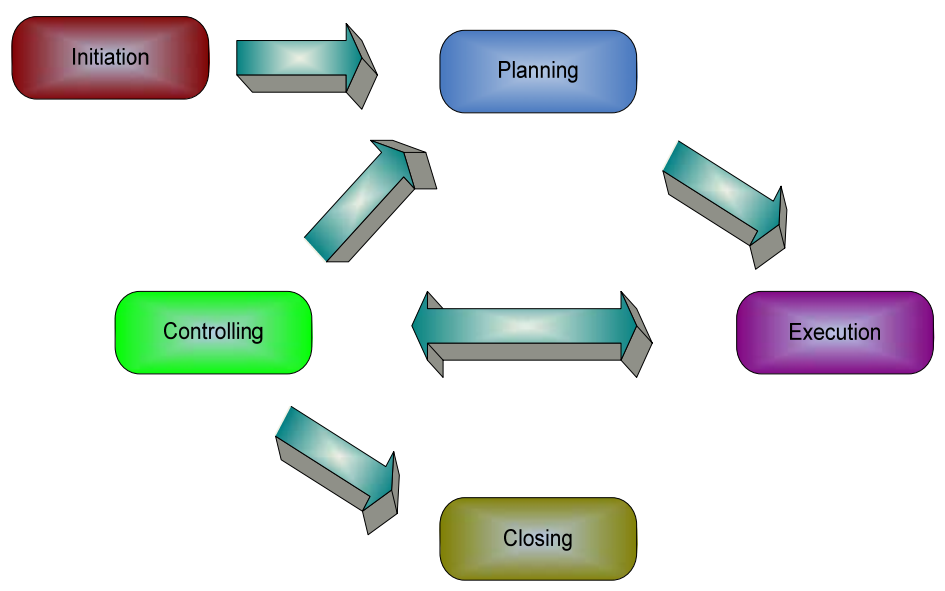

Gambar 1. Bagan proses manajemen proyek PT MSI.

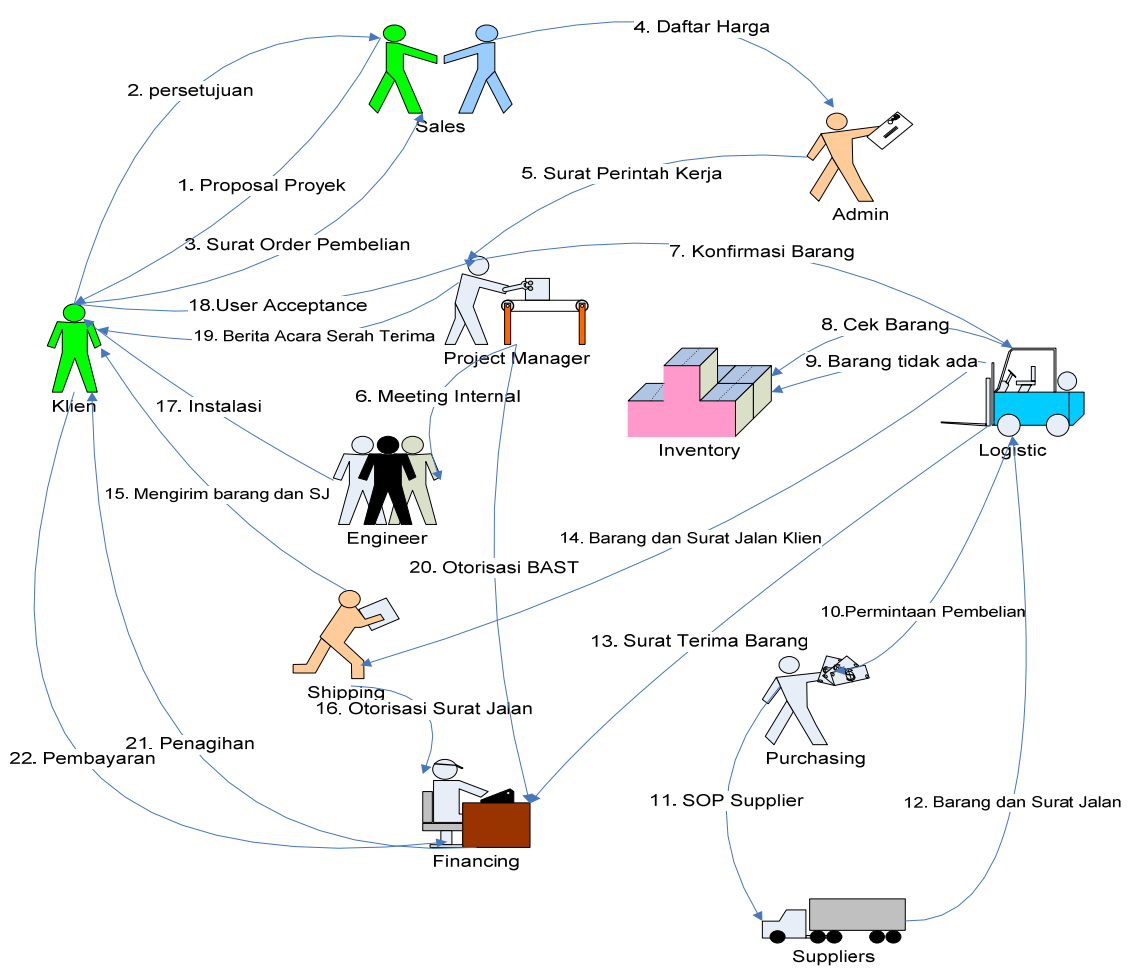

Gambar 2. Rich Picture proses bisnis PT MSI.

\section{Kebutuhan Proyek Jardiknas}

Kebutuhan sehari-hari para pejabat dan staf Depdiknas terhadap internet semakin meningkat, namun demikian hingga saat ini LAN yang dibangun oleh masing-masing unit belum menunjukkan adanya kesatuan jejaring yang diperlukan dalam mendukung layanan Depdiknas kepada publik. Oleh 
karena itu, Pustekkom sebagai pengelola TIK Depdiknas memandang penting untuk melakukan penataan LAN di seluruh gedung di dalam komplek Depdiknas agar komunikasi data dan informasi antar unit-unit utama dapat berjalan lancar dan efektif.

Jadwal pelaksanaan pekerjaaan proyek Jardiknas ini sebagai berikut (Tabel 1):

Tabel 1

Jadwal Pelaksanaan Pekerjaan Proyek Jardiknas

\begin{tabular}{|c|c|c|c|c|c|c|}
\hline \multicolumn{3}{|c|}{ Jadwal Estimasi } & \multicolumn{4}{|c|}{ Minggu } \\
\hline No. & Deskripsi Pekerjaan & Durasi & 1 & 2 & 3 & 4 \\
\hline \multirow[t]{3}{*}{$\mathbf{I}$} & Preparation & & & & & \\
\hline & a. Assessment Network Jardiknas & 2 hari & & & & \\
\hline & b. Standarisasi fitur dan Kebijakan peralatan & 2 hari & & & & \\
\hline \multirow[t]{3}{*}{ II } & Delivery & & & & & \\
\hline & a. Pengiriman Barang & 1 minggu & & & & \\
\hline & b. Laporan pengiriman & 1 hari & & & & \\
\hline \multirow[t]{7}{*}{ III } & Deployment & & & & & \\
\hline & a. Installasi sistem kabel & 1 minggu & & & & \\
\hline & b. Installasi \& Konfigurasi OAW-6000 & 2 minggu & & & & \\
\hline & c. Installasi \& Konfigurasi Access Point AP 41 & 2 minggu & & & & \\
\hline & d. Installasi \& Konfigurasi Captive Portal & 2 minggu & & & & \\
\hline & e. Installasi \& Konfigurasi Akses Switch OS-6400-24 & 2 minggu & & & & \\
\hline & f. Test dan Integrasi & 2 hari & & & & \\
\hline \multirow[t]{3}{*}{ IV } & Acceptance test & & & & & \\
\hline & a. Uji Test \& Uji Fungsi & 3 hari & & & & \\
\hline & b. Dokumentasi & 2 hari & & & & \\
\hline V & Training & 2 hari & & & & \\
\hline
\end{tabular}

Tabel 4 berikut memuat 11 matrix berdasarkan kategori resiko ekonomi proyek jardiknas.

Tabel 4

11 Matrix Berdasarkan Kategori Resiko Ekonomi Proyek Jardiknas

\begin{tabular}{clllll}
\hline Probability & \multicolumn{7}{c}{ Impact } \\
\cline { 2 - 6 } & Very Low (1) & Low (2) & Medium (3) & High (4) & Very High (5) \\
\hline Very High (5) & $(\mathrm{y})$ & $(\mathrm{z})$ & $(\mathrm{z})$ & $(\mathrm{z})$ & $(\mathrm{z})$ \\
\hline High (4) & $(\mathrm{x})$ & $(\mathrm{y})$ & $(\mathrm{z})$ & $(\mathrm{z})$ & $(\mathrm{z})$ \\
\hline Medium (3) & $(\mathrm{x})$ & $(\mathrm{y})$ & $(\mathrm{y})$ & $(\mathrm{z})$ & $(\mathrm{z})$ \\
\hline Low (2) & $(\mathrm{x})$ & $(\mathrm{x})$ & $(\mathrm{y})$ & $(\mathrm{y})$ & $(\mathrm{z})$ \\
\hline Very Low (1) & $(\mathrm{x})$ & $(\mathrm{x})$ & $(\mathrm{x})$ & $(\mathrm{x})$ & $(\mathrm{y})$ \\
\hline
\end{tabular}




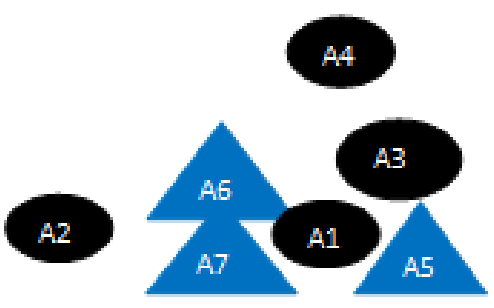

Keterangan:

(x) : low risk

(y) : medium risk

(z) : high risk

: Resiko ukuran (size risk)
: Resiko Sumber daya (resource risk)

\section{Identifikasi Resiko Proyek RSJPDHK}

Dalam mengumpulkan data yang dibutuhkan, penulis melakukan wawancara serta pengisian kuisioner oleh Project Manager dan teknisi PT Mitra Solusi Infokom. Dalam identifikasi resiko, penulis menggunakan faktor-faktor resiko proyek TI yang diadaptasi dari hasil study Zhang Xian Lu dan Lee Jia Pei (2008) yang mengelompokkan resiko proyek TI menjadi tiga kategori umum, yaitu economic risk, organizational risk dan technological risk.

\section{Kompleksitas Lingkungan (Environmental complexity)}

Lokasi yang kurang mendukung - lokasi yang kurang mendukung menyebabkan pengerjaan proyek menjadi sulit untuk dilaksanakan, hal ini dapat dikarenakan kondisi bangunan yang kurang mendukung dalam pelaksanaan proyek. Dalam hal ini MSI melakukan survey ke lokasi proyek dan membuat design implementasi.

Sulitnya mendapatkan informasi dari klien - informasi dari klien merupakan bagian yang berperan penting dalam menentukan arus pelaksanaan proyek, di mana perlu adanya perolehan informasi yang jelas dari klien. Informasi dibutuhkan agar pengerjaan proyek menjadi lebih terarah, dalam hal ini perusahaan merencanakan jadwal pertemuan terlebih dahulu dengan pihak klien.

Komunikasi yang tidak efektif - komunikasi yang tidak efektif dapat menghambat jalannya proyek. Hal ini bisa disebabkan karena adanya kesalahan informasi yang diberikan atau kesalahpahaman yang terjadi antara klien dan Project Manager, serta anggota tim yang lain. Dalam hal untuk mengurangi terjadinya hal diatas, MSI melakukan antisipasi yang dilakukan dengan cara meminta informasi yang sejelas-jelasnya dan merespon dari setiap informasi yang telah diberikan.

\section{Jadwal Pelaksanaan Pekerjaan Proyek RSJPDHK}

Jadwal pelaksanaan pekerjaaan jaringan ini akan dilakukan sebagaimana yang ditunjukkan pada Tabel 5 di bawah ini: 
Tabel 5

Jadwal Pelaksanaan Pekerjaan Proyek RSJPDHK

\begin{tabular}{|c|c|c|c|c|c|c|}
\hline & \multicolumn{2}{|l|}{ Jadwal Estimasi } & \multicolumn{4}{|c|}{ Minggu } \\
\hline No. & Deskripsi Pekerjaan & Durasi & 1 & 2 & 3 & 4 \\
\hline \multirow{2}{*}{\multicolumn{7}{|c|}{ Persiapan }} \\
\hline & & & & & & \\
\hline & a. Ordering peralatan ke principal & 4 minggu & & & & \\
\hline & b. Survey lapangan data center & 4 minggu & & & & \\
\hline & c. Fitur - fitur dan kebijakan & 2 minggu & & & & \\
\hline
\end{tabular}

II

\begin{tabular}{|c|c|c|}
\hline & \multicolumn{2}{|l|}{ Delivery } \\
\hline & a. Pengiriman barang & 2 hari \\
\hline & b. Laporan pengiriman & 1 hari \\
\hline \multicolumn{3}{|l|}{ III } \\
\hline & \multicolumn{2}{|l|}{ Deployment } \\
\hline & a. Instalasi Cabling \& Rack & 6 minggu \\
\hline & b. Instalasi Core Switch & 2 hari \\
\hline & c. Instalasi Distribution\&Access Switch & 7 hari \\
\hline & d. Instalasi Internet Router \& Security & 1 hari \\
\hline \multirow{2}{*}{\multicolumn{3}{|c|}{ Miaration Plan }} \\
\hline & \multicolumn{2}{|l|}{ Migration Plan } \\
\hline & a. Assessment kondisi yang ada & 7 hari \\
\hline & b. POC (Proof of Concept) & 2 hari \\
\hline & c. Migration & 1 hari \\
\hline
\end{tabular}

IV

Acceptance Test

a. User Acceptance Test (UAT) 1 hari

b. Dokumentasi 3 hari

c. Training 3 hari

Tabel 6 berikut memuat Matrix Kategori Resiko Teknologi Proyek RSJPDHK.

Tabel 6

Matrix Berdasarkan Kategori Resiko Teknologi Proyek RSJPDHK

\begin{tabular}{cccccc}
\hline \multirow{2}{*}{ Probability } & \multicolumn{5}{c}{ Impact } \\
\cline { 2 - 6 } & Very Low (1) & Low (2) & Medium (3) & High (4) & Very High (5) \\
\hline Very High (5) & $(\mathrm{y})$ & $(\mathrm{z})$ & $(\mathrm{z})$ & $(\mathrm{z})$ & $(\mathrm{z})$ \\
& & & & $(\mathrm{z})$ & \\
\hline High (4) & $(\mathrm{x})$ & $(\mathrm{y})$ & $(\mathrm{z})$ & & \\
\hline
\end{tabular}




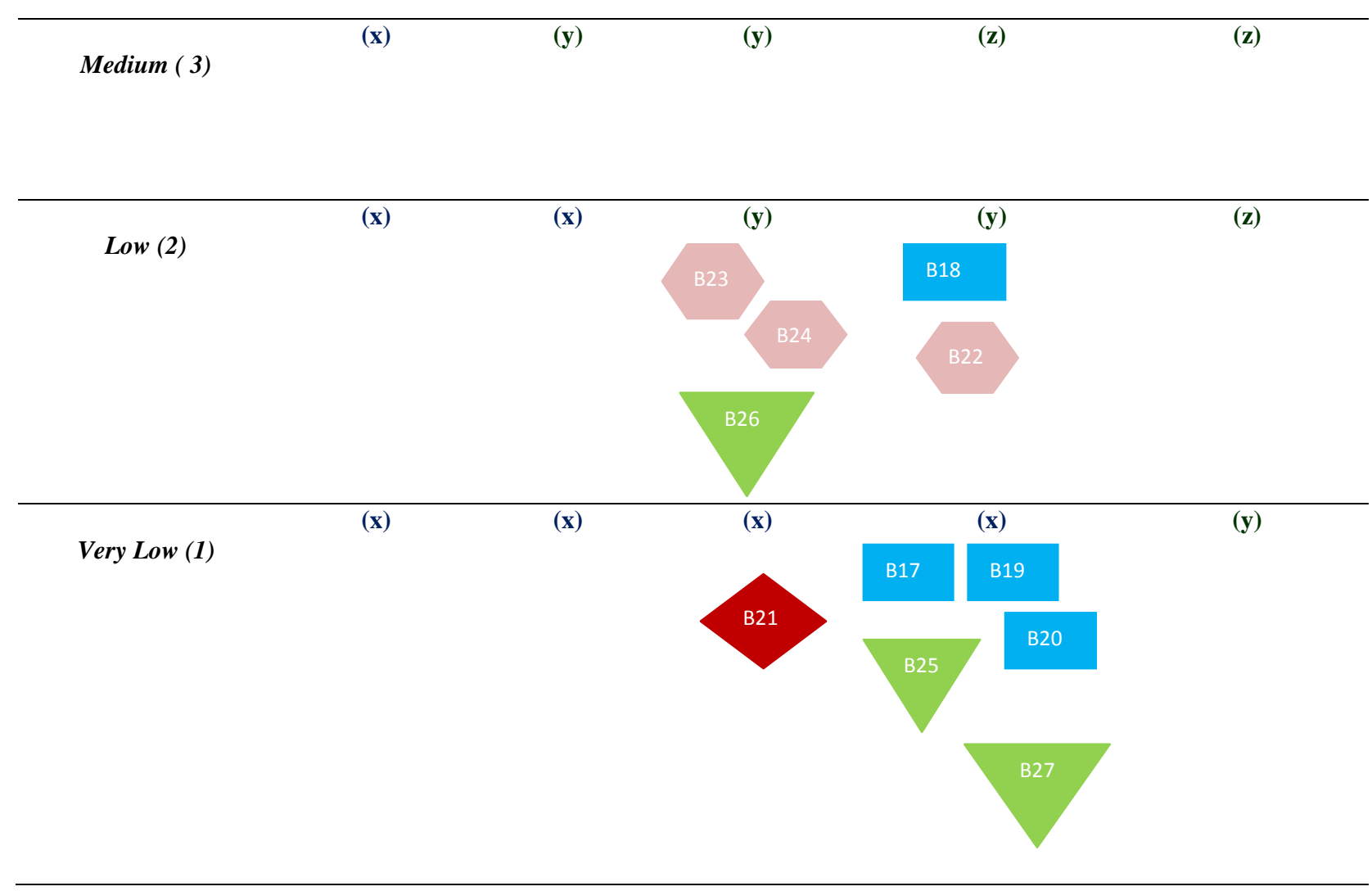

Keterangan:

(x) : low risk

(y) : medium risk

(z) : high risk

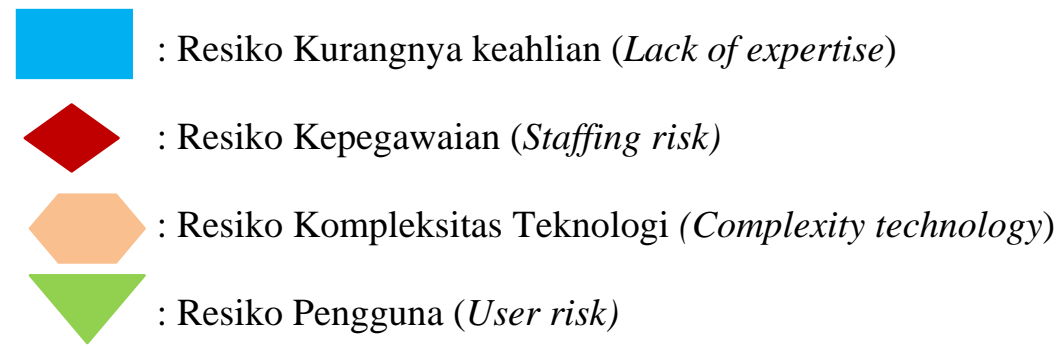

\section{PENUTUP}

Penelitian telah dilakukan pada salah satu perusahaan swasta di Indonesia, yaitu PT MSI, dengan cara mengukur resiko manajemen proyek teknologi informasi di perusahaan. Berdasarkan hasil penelitian dapat disimpulkan beberapa hal.

Pertama, perusahaan sudah menjadikan teknologi informasi sebagai pendukung dalam menjalankan aktivitas proyek perusahaan. 
Kedua, perusahaan sudah melakukan suatu proses manajemen proyek, yaitu proses inisiasi, perencanaan, pelaksanaan dan pengendalian, evaluasi proyek dan penutupan proyek. Namun perusahaan belum melakukan pengukuran terhadap resiko manajemen proyek TI.

Ketiga, resiko-resiko telah ditemukan pada level high (unacceptable) pada proyek yang terkait dengan PT MSI. Pada Proyek Jardiknas terjadi jadwal proyek yang kurang realistis. Resiko ini tergolong dalam level tinggi karena adanya salah satu gedung di Jardiknas yang masih direnovasi. Oleh karena itu, pelaksanaan instalasi perangkat jaringan menjadi tertunda karena harus menunggu sampai kondisi lapangan sudah selesai direnovasi. Hal ini mengakibatkan terjadinya perubahan jadwal dari estimasi awal. Lokasi proyek yang kurang mendukung menentukan pelaksanan proyek. Dalam pengerjaan proyek Jardiknas, resiko ini tergolong dalam level tinggi karena kondisi lapangan yang menyulitkan tim proyek memasang perangkat jaringan. Tim proyek harus berhati-hati dalam menentukan lokasi dimana akan dipasang perangkat. Hal ini dapat membawa dampak yang substansial karena lokasi proyek yang kurang mendukung sehingga dapat menyebabkan suatu pengerjaan proyek menjadi terhambat bahkan memakan waktu dan biaya yang lebih besar dari yang diestimasi. Selanjutnya pada proyek RSJPDHK, lokasi proyek kurang mendukung. Lokasi yang kurang mendukung dalam proyek RSJPDHK dapat menyebabkan tim proyek cukup kesulitan dalam menentukan jalur kabel saat pelaksanaan proyek terutama karena penarikan kabel tersebut dilakukan antar gedung dan pemasangan kabel tidak boleh mengganggu aktivitas kerja rumah sakit.

Keempat, dengan melakukan proses respon resiko yaitu proses mitigasi , resiko yang akan dihadapi pada pengerjaan proyek akan lebih dapat dikendalikan.

\section{DAFTAR PUSTAKA}

Alberts, C., \& Dorofee, A. (2003). Managing Information Security Risks. MA: Adisson-Wesley.

Jordan, E., \& Silcock, L. (2005). Beating IT Risks. Chichester: John Wiley and Sons.

Laudon, Kenneth C. \& Laudon, Jane P. (2006). Management Information System (9 $9^{\text {th }}$ ed.). New Jersey: Pearson Education International.

Lucas, Henry C. (2000). Information Technology for Management (7th ed.). New York: Mc Graw-Hill/Irwin.

McLeod, Raymond Jr. (2001). Sistem Informasi Manajemen, (ed.8). London: Prentice Hall.

O’Brien, James A. (2006). Introduction to Information System. Essentials for E-Business Enterprise (12th ed.). New York: Mc-Graw-Hill/Irwin.

Thomson, R. \& Cats-Baril., W. (2003). Informtion Technology \& Management, (edisi ke-2). NewYork: McGraw-Hill.

Turban, Rainer, \& Potter. (2003). Introduction to Information Technology, (edisi ke-2). New York: John Wiley and Sons. 